\title{
The Maxwell Demon: a Proposal for Modeling in Ecological Synthesis in Art Practices
}

\author{
Luzilei Aliel (Universidade de São Paulo, São Paulo, São Paulo, Brasil) \\ luzaliel@usp.br \\ Damián Keller (Universidade Federal do Acre, Rio Branco, Acre, Brasil) \\ dkeller@ccrma.stanford.edu \\ Rogério Costa (Universidade de São Paulo, São Paulo, São Paulo, Brasil) \\ rogercos@usp.br
}

\begin{abstract}
This paper aims to expand the research on ecological synthesis models (KELLER, 1999) through the inclusion of improvisation practice. We propose a formalization of creative processes in sonic improvisatory-compositional environments (targeting comprovisation), based on ecologically grounded creative practices. Our approach entails the use of socio-ecological models that deal with complex adaptive systems [SIBERTIN et al., 2011]. We developed a performance/experiment called The Maxwell Demon, as a case study. The observations done during the study indicate that imitation is an important strategy for creative activities in socio-ecological systems. Improvisation may provide a relevant sonic content in ecological environments, enhancing their flexibility without losing consistency. Keywords: Comprovisation; Socio-Ecological System; Performance/Experiment
\end{abstract}

O Demônio de Maxwell: uma proposta de Modelagem em Síntese Ecológica em Práticas Artísticas

Resumo: Este artigo procura expandir as pesquisas a respeito dos modelos de síntese ecológica (KELLER, 1999) através da inclusão da prática de improvisação. Propomos uma formalização dos processos criativos em ambientes sonoros improvisatórios-composicionais (objetivando a comprovisação), baseada em práticas criativas ecologicamente fundamentadas. Nossa abordagem implica o uso de modelos sócio-ecológicos que lidam com sistemas complexos adaptativos [SIBERTIN et al., 2011]. Como estudo de caso, desenvolvemos uma performance/experimento intitulada The Maxwell Demon. As observações realizadas durante o estudo indicam que a imitação é uma estratégia importante para as atividades criativas em sistemas sócio-ecológicos. A improvisação pode prover conteúdo sonoro relevante em ambientes ecológicos, aumentando sua flexibilidade sem perder consistência.

Palavras-chave: Comprovisação; Sistema Sócio-Ecológico; Performance/Experimento

\section{Introduction}

This work deals with ecologically grounded creative practice targeting both composition and sonic improvisation (comprovisation). We take as reference complex adaptive systems due to the large number of variables involved in creative musical activities. The use of adaptive systems in artistic dynamically changing contexts are usually approached from a modeling perspective (BARREIRO; KELLER, 2010). Models can be employed to determine the qualitative aspects of socio-ecological dynamics (SIBERTIN-BLANC et al., 2011). We discuss the alignments and deviations of the socio-ecological proposal with current ecocompositional and comprovisational practices. To account for the improvisatory elements involved in ecologically grounded creative practice, we expand the ecocompositional approach laid out by Keller (1999) with a Proposal of Ecological Synthesis Models (PESM). Socio-ecological models were developed to design performances/experiments ${ }^{1}$, usually described as case studies. A study features analytical notes on the creative processes, the interaction strategies, the types of agents and the production of resources. We model, test a observe the outcomes of the PESM in a performance/experiment that uses ecologically grounded comprovisation, The Maxwell Demon (TMD).

\section{1) Socio-Ecological Systems}

Socio-ecological systems are characterized by self-organization and distributed 
control. In socio-ecological systems, social and ecological processes interact at various temporal levels. Models usually encompass multiple agents, each one with diverse and contrasting objectives which can be observed at various spatial and temporal levels (REED, 2008; PAHL-WOSTL, 2007; GIAMPIETRO, 2002). These multiple levels entail emergent structures and functionalities. According to Sibertin-Blanc et al. (2011), a socio-ecological system includes entities and processes, together with relationships between the entities ${ }^{2}$. The relationships among the entities yield instances of entities, which are resources that may appear or may be discarded over time as the state of the system changes. Entities are characterized by properties whose values represent an instance ${ }^{3}$. There are two types of relationships among entities: 1. structural relationships - directly associated to the entities; 2. non-structural relationships - created as a result of the agents' actions. The dynamic character of a socio-ecological system involves processes that may evolve either toward orderly or toward disorganized conditions, impacting both the internal (cognitive) and the external (material) processes. To assess these processes, it is necessary to consider the interactions between the socio-ecological system and the environment.

The concept of activity proposed by Sibertin-Blanc et al. (2011) may help to explain human behaviors within the context of comprovisational practices. The instances of entities help to define either the lack of significance or the relevance of the resources within the sonic activity, leading to higher or to lower creative potentials. Exchanges of instances of entities ${ }^{4}$ (including material and cognitive resources) do not occur in isolation. Creative factors tend to influence each other. For example, the choice of a material resource is directly linked to a cognitive or a behavioral state (implying a subsequent change in the socio-ecological system). These choices impact the behaviors of the stakeholders. In turn, each aesthetic choice may be perceived as positive or negative, thus influencing whether a shared resource will be developed and integrated into a creative product or whether it will be ignored by the stakeholders.

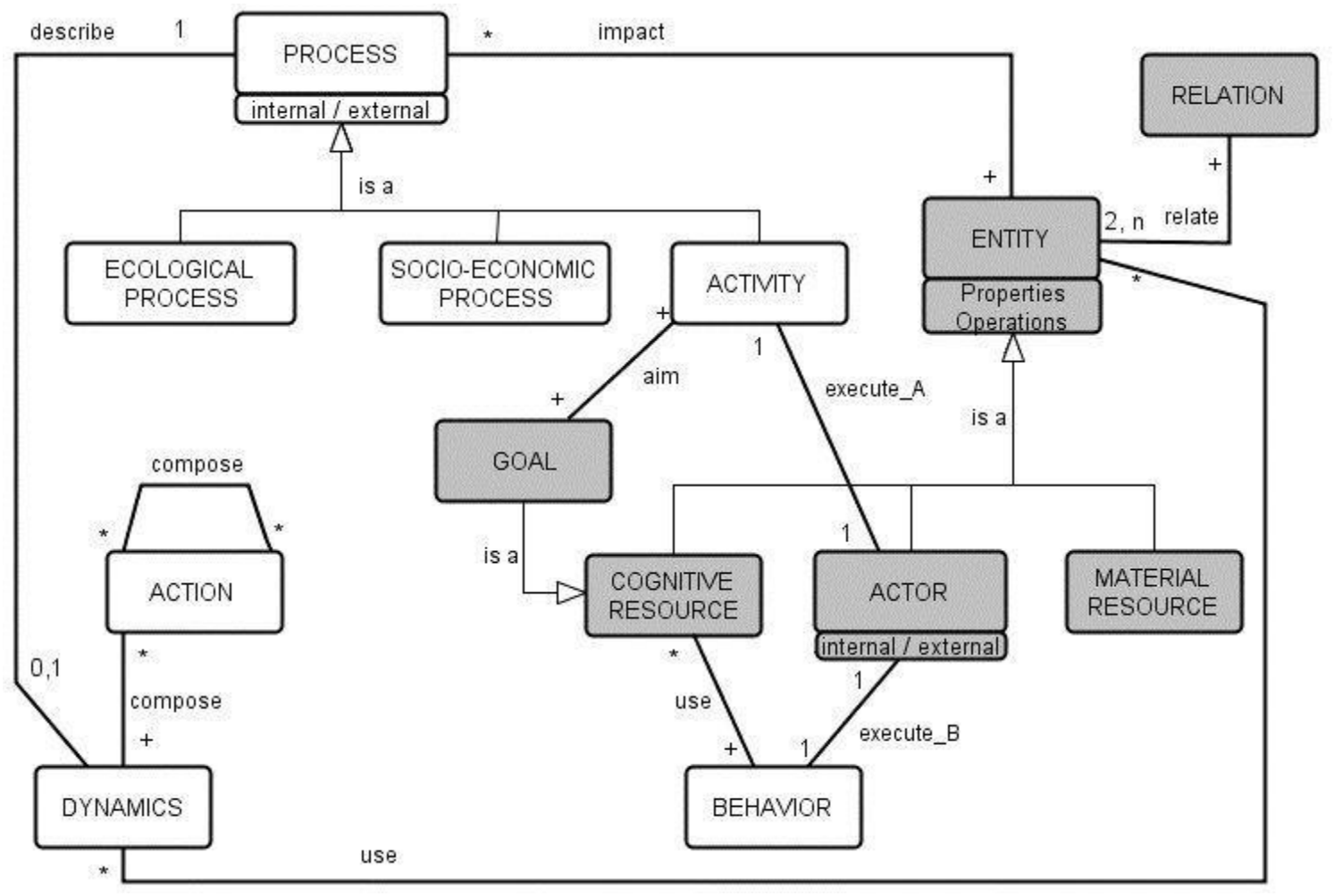

Fig. 1: A model of socio-ecological systems proposed by Sibertin-Blanc et al. (2011). 
A close look at the model proposed by Sibertin-Blanc et al. unveils alignments and deviations from ecologically grounded models applied in music making (DI SCIPIO, 2014; FERRAZ; KELLER, 2014; KELLER et al., 2014). Figure 2 highlights the commonalities of both approaches. Eco-based models encompass resources (1), activities (2) and by-products (3). These elements are shared by both frameworks (despite some differences in terminology). Resources are consumed during the execution of activities, thus yielding by-products (entities in Sibertin-Blanc's nomenclature). A key contribution of eco-based practices is a raised awareness of the mutual relationships among the agents behaviors and the material resources. This is usually expressed by feedback paths linking the agent's actions and the environmental impacts. The implication being that resources are not just consumed, they are also produced by the agents. This feature is lacking in Sibertin-Blanc's model. Furthermore, recent eco-based proposals have stressed the long-term impact of creative activities on the environment - most notably through the incorporation of sustainable support strategies. This is usually represented by a separation of three different types of byproducts: creative products, new resources and creative waste. Creative waste encompasses byproducts that are not incorporated in the final creative results (FERRAZ; KELLER, 2014). These byproducts may be used by the same stakeholders in other activities or may be employed by other agents through sharing. Nevertheless, the rejected material outcomes also have the potential to accumulate with harmful effects on the local environment.

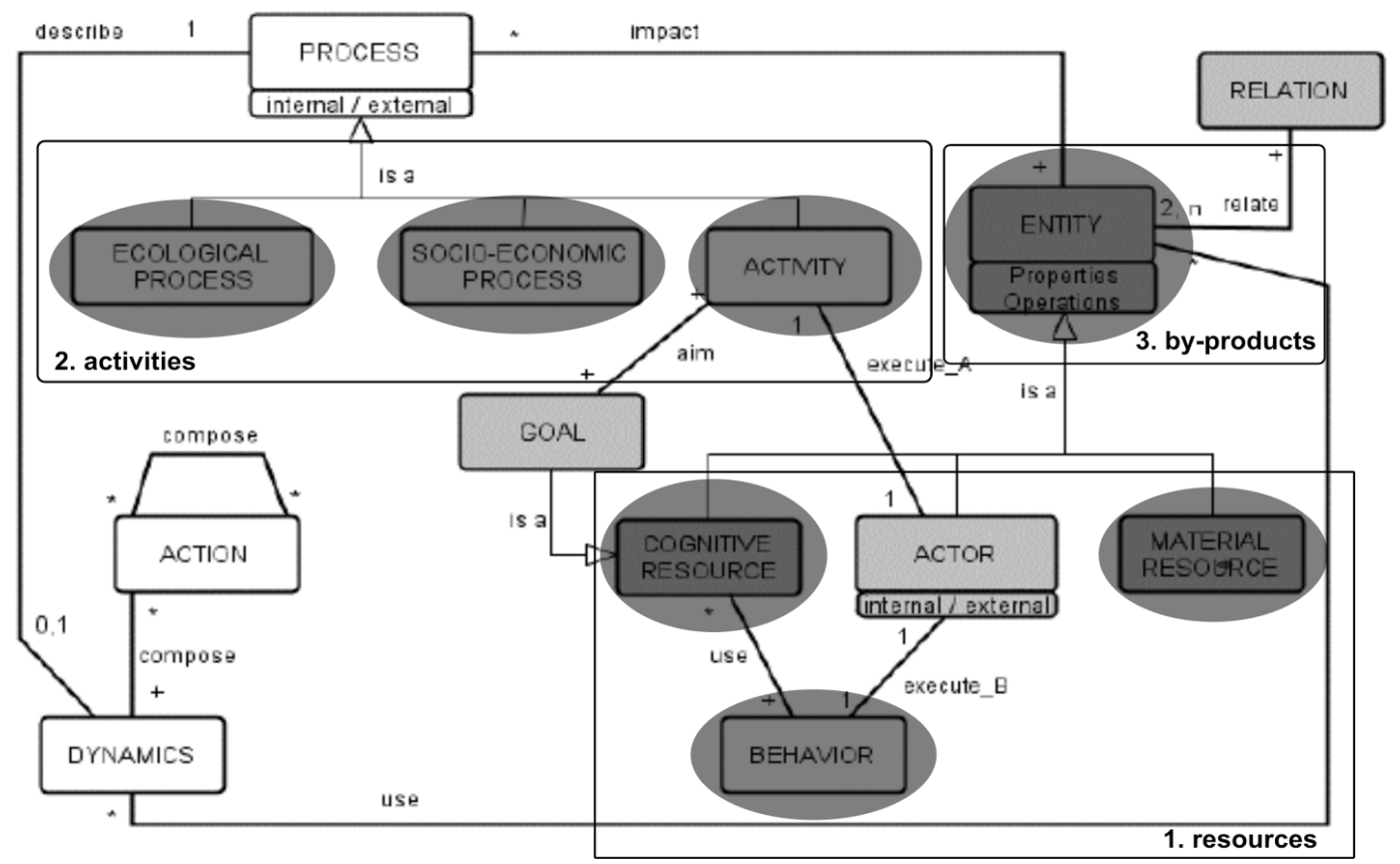

Fig 2. Establishing conceptual parallels between Sibertin-Blanc and coauthors' model (2011) and the ecocompositional proposals (KELLER, 1999; KELLER; CAPASSO, 2006; KELLER et al., 2014).

Approaching socio-ecological systems from an ecocompositional perspective may foster viable methodological formulations for artistic goals. Sibertin-Blanc et. al (2011) develop a scheme that explains how certain behaviors are linked to actions and entities. Interactions among agents are at the core of the creative activity. Their model proposes behaviors capable of influencing other agents' actions. The system entities can be understood as material and cognitive resources, resulting from interactions among agents. Their features are aligned with collective musical activities in which the material resources include the tools, while the cognitive resources are the mechanisms by which the agents interpret and manipulate their environment. Just like in previous ecologically oriented proposals (BURT- 
NER, 2005; KELLER, 2000; KELLER; CAPASSO, 2006), the authors argue that ecological and social processes provide grounding for cognitive processes, externalized as activity. For Sibertin-Blanc et. al (2011), activities target objectives while shaping the behaviors of the agents. Through mutual influences, the agents tend to project goals that may become targets of the creative endeavors. Both material and cognitive resources are usually discovered through activities involving cycles of actions, dismissals or rewards.

The concept of activity in ecologically grounded musical practices contributes with the expansion of the available creative strategies. Adopting the framework laid out by Basanta (2010), Di Scipio (2008) and Keller and Capasso (2006), the use of the term activity as proposed by Sibertin-Blanc can be questioned. The assumption that the agents' activities imply simple and clear goals corresponds to a problem-oriented view of social interactions defined as teleological by Fantauzzacoffin and Rogers (2013). Behaviors associated with the achievement of goals by a single agent provide just one possible line of inquiry. Creative activities encompass a wide range of actions that aim to increase the knowledge of the resources. No effective creative outcome can be achieved without a previous acquaintance with the materials. This procedural path is better described as exploratory or epistemic activity (KELLER et al. 2014; KIRSCH; MAGLIO, 1994). Furthermore, musical activities involve actions that may yield rejections or rewards. When dealing with collective composing and improvising, material resources - entailing material and behavioral choices - usually result from complex interactions. Hence, creative decision-making relies on multiple factors that unfold during the interactions among the stakeholders. For example, an agent can be biased toward a specific goal through multiple exposures to a recurring event. Alternatively, based on previous interactions with other agents while exchanging resources, she may decide to forage for new material resources.

The concept of creative sonic potential ${ }^{5}$ can be employed when a sonic feature stands out from a sound mass, leading to actions that impact the sonic organization. Part of the decision-making processes are due to the imitation of the material resources produced and developed during the performance by other agents. High levels of creative potential are easily measurable because it is possible to point out when (time) and who (which agent) produced a resource that enables imitation, repetition or transformation by other agents. High creative potentials may be associated with rational choices on the part of the agents (based on explicit knowledge), intuitive decisions (based on tacit knowledge) or unpredictable actions (due to the influence of random factors). When dealing with sound masses, creative sonic potentials may change due to processes involving imitation of resources produced by other agents or due to mimesis of the agent's own previous behaviors targeting states of stasis (involving small changes in parameters such as pitch or rhythm, for example). High creative potentials are characterized by cyclical processes which are usually easy to recognize. These processes can be observed through their impact on the masses of sound but they are hard to analyze through the agents' objectives or goals. The relevance factor is also directly related to the manipulation of the material resources. If the material resources become more organized, they tend to be more relevant to the agents participating in the creative activity. Material resources may become stable when they are consistently relevant. However, some material resources may eventually be discarded due to a loss of relevance.

\section{Ecological Synthesis Models (PESM)}

The ecological approach is based on the premise that all sonic models should be restricted to ecologically feasible events (KELLER, 1999; KELLER, 2000; KELLER; CAPAS- 
SO, 2006). Ecological validity is defined by observations of interactions occurring in the environment, i.e. by data of interactions among agents and objects. The individual's actions on the environment and the influence of the environment on the individual determine a process ofpattern formation. This process can be modeled by algorithmic tools (KELLER, 1999: p. 23). Keller's (1999) ecological modeling conceptualizes the creative use of environmental sounds, employing spatial locations consistent with the sound sources behaviors and applying ecologically viable sonic transformations. Keller (1999) argues that synthesized sounds can expand the compositional resources without compromising the meaning of the sonic events, hence providing unique opportunities for creative action. The author puts forth two techniques to enhance the creative possibilities in ecologically based scenarios: 1) Generic Physical Models, 2) Control of Meso-Level Granular Sample Sets (see KELLER, 1999 for a detailed description). The ecological approach stresses the usage of the material resources, adopting multiple creative paths: 1) local environments yield resources where the agents carry out their activities; 2) synthesized environments incorporate resources through digital audio processing; 3) meta-soundscapes encompass resources originated both from local and from remote environments (ALIEL; FORNARI, 2013). Other materials result from the interactions among human beings, encompassing at least two strategies: 1) exploratory activity: the agent's ability to discover material resources while interacting with the environment, with other agents or with gelassenheit ${ }^{6}$ entities; and 2) epistemic activity: empirical knowledge construction through the production of creative cognitive resources (KELLER et al., 2010; KIRSCH; MAGLIO, 1994).

The difference between exploratory and epistemic activity is subtle but significant for creative endeavors. Both activities are tied to the exploration of the environment. Nevertheless, while exploratory (or foraging) actions produce material resources that can be employed for creative purposes, epistemic actions only increase the cognitive potential for creative outcomes without yielding material byproducts. Hence, epistemic activity furnishes only cognitive resources, while exploratory activity provides both material and cognitive resources. The PESM has the function of expanding the range of compositional strategies (in this case also of improvisation). In the case of exploratory activities, the stakeholders' actions aim to discover material resources through exploration of the environment. These processes can involve imitation and trial and error. Whether the resources are reused or discarded, the agents' actions yield knowledge that is directly applied in the creative outcome. Epistemic activities encompass actions that may involve deduction, induction, imitation and exploration through trial and error. These activities do not occur in isolation, they complement each other making the process dynamic, iterative and difficult to measure. Given this context, the cognitive resources - or instances of entities (SIBERTIN-BLANC et al., 2011) - may not be stable for a sufficient period to allow evaluation or measurement.

\section{Comprovisation in PESM}

The practice of comprovisation is an artistic strategy encompassing a mix of musical composition and musical improvisation. The term comprovisation has no consensual definition and its origins can be traced back to the improvisatory proposals of the sixties including but not limited to artistic groups such as the Scratch Orchestra and the ensemble Musica Elettronica Viva (CARDEW, 1969; CURRAN; TEITELBAUM, 1989). Current comprovisational approaches are documented in Fujak (2011), Hannan (2006), Bhagwati (2014), Dudas (2010) and Aliel et al. (in press). We describe the key features of each perspective.

Fujak (2011) proposes a broad definition of comprovisation with the purpose of 
emancipating and legitimizing the artistic practices being carried out in the Slavic Region. For this group of artists, comprovisation can be understood as an aesthetic stance involving two aspects.

1. A transparent principle that articulates contemporary art in analogy with life situations as a result of what is rigorously planned and what is subject to unpredictable changes. Artists are expected to respond operationally and creatively to these challenges;

2. A conscious choice of compositional processes encompassing situated antecedents, principles, guidelines and improvisation within the context of contemporary musical intertextuality based on technological resources.

Hannan (2006) suggests that although there are random and intuitive elements in previous musical practices, the practice of comprovisation entails a new compositional approach. He lists three strategies that characterize comprovisation.

1. The adoption of intentionality as a basis for sonic organizational processes;

2. The adoption of a research methodology: a comprovisation project should make the choices and the structural relationships between movements, sections and phrases explicit.

3. The use of sonic materials recorded from instrumental improvisations.

Bhagwati (2014) proposes a "notation perspective" of comprovisation, which serves to structure the explicit and reproducible elements (composition) and the contingencies (improvisation) in his proposal. He states that comprovisational practices are conceptually opposed to what he calls the "central hearing perspective"". For Bhagwati, comprovisation practices encompass four modalities.

1. "Free" forms, featuring organic growth or gradual disintegration;

2. Use of notation techniques to support for structural heterarchies or hierarchies (deterministic composition) within open structures (improvisation);

3. Practices that allow horizontal layerings of sound events (polyphonic textures);

4. Elaboration of structural flowcharts featuring multiple levels, which can result in diverse forms of participation by the musicians;

Dudas (2010) highlights the technological factors featured in comprovisation and proposes two strategies to integrate these resources.

1. Computer support, including the aesthetics related to interactive art stemming from the acoustic-instrumental tradition;

2. Improvisation with technological tools to create pre-compositional materials;

Aliel et al. (in press) suggest that the ecological perspectives may provide a significant contribution to comprovisational practices. They propose three strategies.

1. Adoption of procedures that present guideline plans (planned actions) and contingencies (actions that can not be defined before their execution);

2. Allow intentional actions during a performance (choice of improvised actions);

3. Introduce stochastic sonic organizations by means of electronic/digital or acoustic resources;

From an ecological perspective on comprovisation (ALIEL et al., 2017), creative actions are carried out through guideline plans (composition) and contingencies (improvisation) keeping a tight relationship between the source materials and the environmental features. The creative factor place (RHODES, 1961) provides the milieu where the actions, interactions, reactions and divergencies among the stakeholders occur. In comprovisation, the guideline plans establish persistent rules of sonic organization (impacting mass and form), of resource usage (impacting the procedures adopted by the agents), while contingen- 
cies deal with the use of volatile resources. A recent example of a comprovisational study is Citations (ALIEL et al., 2015). Citations features live electronics and voice. The piece is structured to encourage multiple interactions among the agents while targeting the potentialities of the environmental resources. Citations includes a guideline plan and a process of accumulation of multiple sonic layers ${ }^{8}$ (ALIEL et al., 2015; BHAGWATI, 2014; KELLER, 2000). The procedure consist of adding layers of material resources (through looping of voice sounds and electronic processing), aiming to obtain a sonic ecosystem through feedback processes (see also Audible Ecosystemics - DI SCIPIO, 2003). Recordings of multiple performances are added as sonic layers while digital audio processing modifies the acoustic sources. The sonic outcome avoids the auditory recognition of the original sources.

\section{Case study The Maxwell Demon: Materials and Methods}

\subsection{Proposal}

The Maxwell's Demon (TMD) is a comprovisation inspired by James Clerk Maxwell's 1871 experiment. In Maxwell's mental experiment, the imaginary entity (demon) produces actions capable of separating molecules at different stages of temperature (which in our reality is impractical, but viable from a theoretical physics perspective), producing a condition conflicting with the second law of thermodynamics, that proposes that environments with varying temperatures tend to balance due to entropy. Maxwell's mental experiment can be represented as a box with a divider placed in the middle, separating it two compartments, left and right. This partition has a door that can be opened and closed by an imaginary being, called Maxwell's Demon. The demon only allows the fastest molecules to flow to one side of the chamber. Only the slower molecules flow to the other side, gradually causing one side to warm up, while the other remains cool.

TMD proposes an artistic metaphor focused on sound (rather than thermodynamics) to simulate an imaginary being - a stochastic algorithm - that seeks to control the sonic outcome to increase or reduce its entropy. Conceptually, we treat automated stochastic algorithms as gelassenheit entities [HEIDEGGER, 1985; KOUTSOMICHALIS, 2011]. The gelassenheit or demon entity provides stochastic modifications of the sonic content without requiring bio-agents interventions. A gelassenheit entity has an "independence"" in time and space. Its dynamics are established by stochastic processes. Since a gelassenheit entity produces sonic results that use the material resources produced by the agents, this seems to be analogous to Maxwell's imaginary entity. This is a non-biological agent capable of influencing the system's properties. The difference between an imaginary entity (as an agent) and the biological agents is the interference of interactive actions. While the biological agents yield cognitive resources that can change the behaviors, a gelassenheit entity is governed by automated mathematical calculations ignoring the behaviors of the other agents. Biological agents may be influenced by the content generated by the machine possibly leading to a more organized system - featuring diversity of material resources through a higher level of pregnancy. Although each agent contained in this environment has a range of creative sonic potentials, the gelassenheit (pregnancy, dynamic or material resources) enforces the selection of specific material resources. Even within a highly entropic environment, the macro organization may be influenced by the entity.

\subsection{Design/Implementation - Guidelines Plan and Contingency}

5.2.1 Materials and equipment: A computer running the TMD algorithm is connected to 
four loudspeakers. The loudspeakers are placed at the four corners of the studio where the performance/experiment takes place. All participants (musicians and non-musicians) are given a mobile phone with a Pure Data (PD) (PUCKETTE, 1997) patch adapted for MobMuPlat (IGLESIAS, 2016).

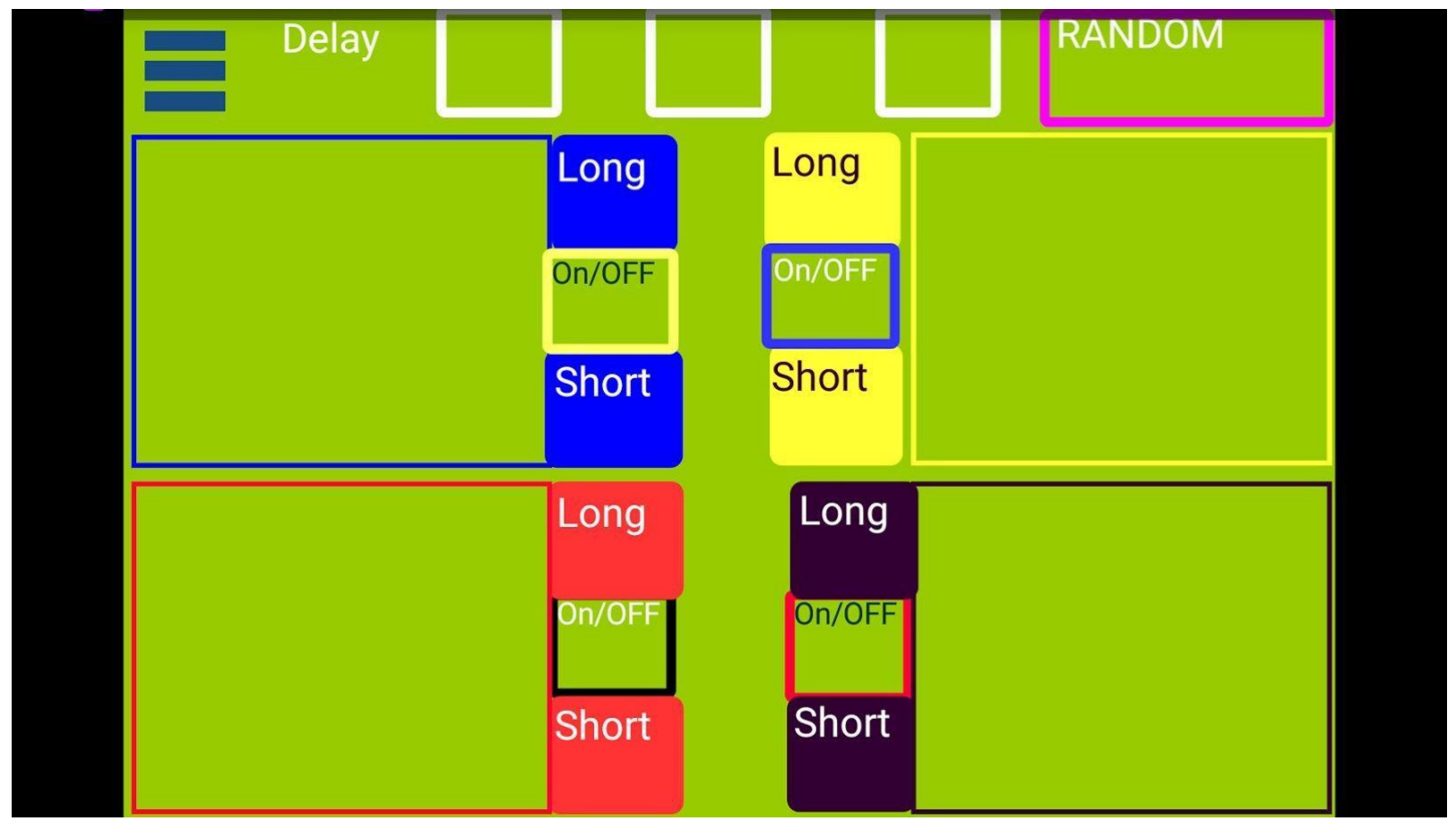

Fig. 3. Interface of the The Maxwe/l Demon mobile patch.

5.2.2 Tools: We designed a tool capable of producing sounds, with the following characteristics: 1) easy to manipulate; 2) accessible to all agents (through deployment on mobile platforms based on Android and IOS systems). The mobile screen features four rectangles that act as controllers of additive synthesis oscillators (figure 2). Simultaneous control of up to four banks of oscillators is possible. Four FM synthesis oscillators feature control parameters for frequency, duration and delay. Random processes are triggered by tapping the phone's screen and can be turned on and off at any time. The frequencies vary from 220 Hertz to 1320 Hertz. Frequency increments are associated with gestures from left to right. Beside each rectangle there are three oscillators switches (on/off buttons) and two envelope controllers. One defines attack, decay, sustain and release of short envelopes and the other sets the parameters of long envelopes. The left button at the top of the screen controls a stochastic algorithm driving all the oscillators frequencies. This triggers random changes in each oscillator. The remaining three buttons apply delay on the sound sources. From left to right, the delay durations are $150 \mathrm{~ms} ., 300 \mathrm{~ms}$. and $750 \mathrm{~ms}$.

We also developed a Pure Data patch (figure 3) that runs on a desktop computer with similar features as the algorithms for the mobiles. This patch features four oscillators that drive additive amplitude (AM) synthesis algorithms. Each oscillator has three parameters that modify the amplitude of the wave. The oscillators are controlled by a random algorithm, which allows variations between $50 \mathrm{hz}$ and $2000 \mathrm{hz}$. A dynamic envelope controller (ADSR) sets attack, decay, sustain and release of the sonic events. This envelope algorithm is also stochastically controlled yielding a variety of attack,decay and sustain profiles. All sound sources are processed, including high-pass filtering, delay and reverberation. Delay durations vary randomly between no delay and $5000 \mathrm{~ms}$. 


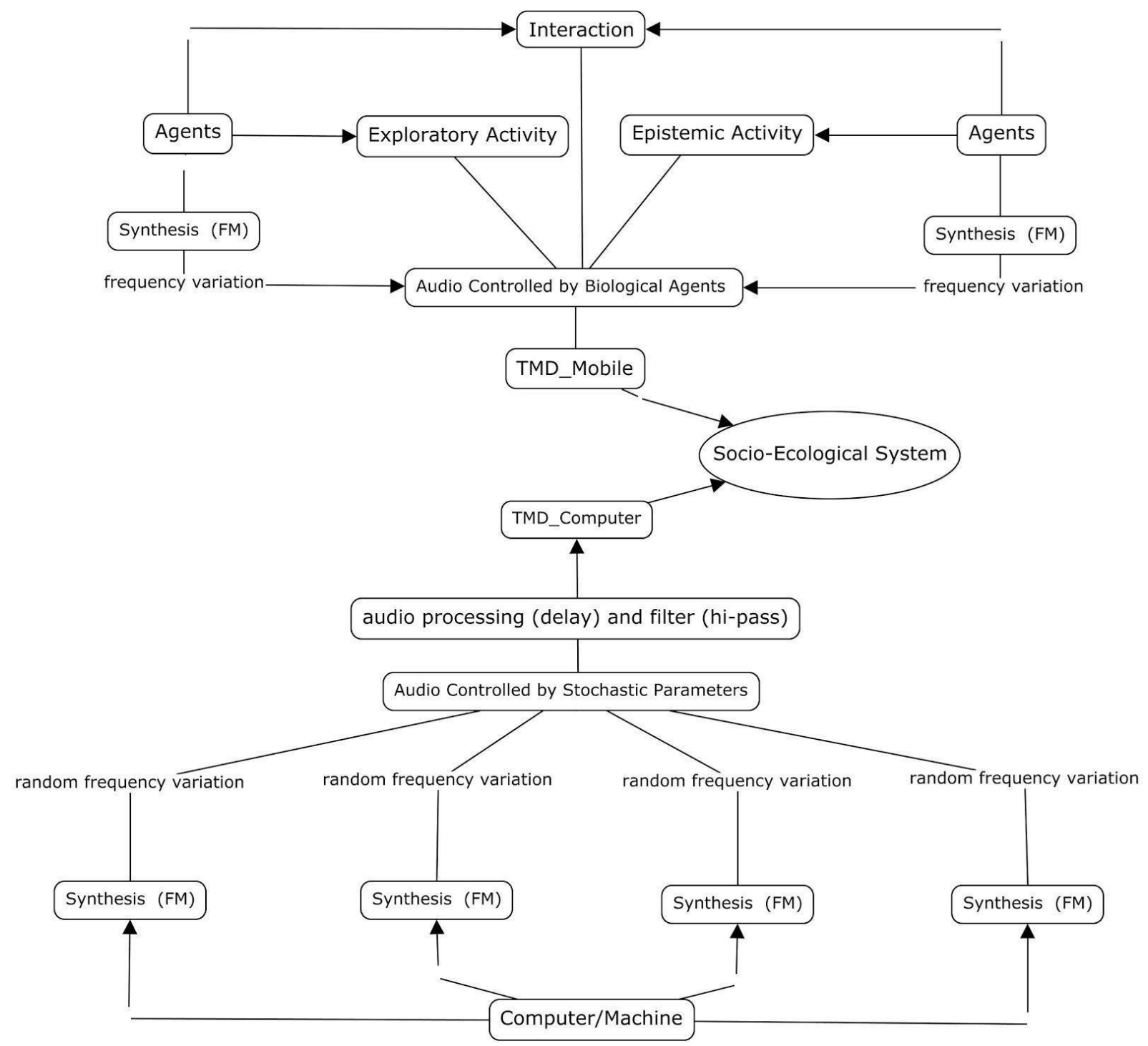

Fig. 4. Pure Data patch interface on a desktop computer used in The Maxwe/l Demon.

5.2.3 Sonic materials. We use an emulated bell (based on FM) that plays at the beginning of the performance/experiment. The session ends when the bell is heard again. This sound is triggered by a PD patch. The entire performance takes seven minutes. Part of the sonic content that occurs between the ringing of the bells features contingencies resulting from interactions and sound discovery. Location and participants. The experiment was performed in a small-sized studio of approximately 10x07 meters. Having Maxwell's procedures as inspiration, we selected two types of participants, some with musical training and some with little or no previous music knowledge (five musicians and two non-musicians). All participants had college education. Non-musicians possessed familiarity with basic musical concepts but had no formal training. Among the non-musicians, there were three women - ages 25, 32 and 35. The musicians were four men, ages 26 to 58 and one woman (22 years old), with music training and previous musical experience varying from 10 to 30 years.

5.2.4 Procedures. Procedurally, TMD is a comprovisation (ALIEL et al., in press]. We adopt a socio-ecological approach highlighting interactions among the agents and the algorithms. The performance/experience is guided by the definition a scenario (SIBERTIN-BLANC., 2011), featuring a seven-minute comprovisation with mobile devices. We created a guideline plan to indicate which events would be designed (composed resources), leaving other 
aspects to occur freely (improvised resources or contingencies). The guidelines given to the agents are: "move through the space and use the devices to produce sounds". The participants move freely within the performance space. After ringing the bell, the computer triggers the preset parameters defining the number of oscillators, the choice of pitches, dynamics, durations and controlling the audio processing (delay settings). Therefore, the technological support for the performance/sound experiment is fully automated. At the second ringing of the bell, the session finalizes.

5.2.5 Assessment. Data was collected through interviews with the participants, on-site observations and analysis of audio and video recordings. The observations include: 1) initial state of the entities; 2) creative processes dynamics; and 3) impact of external processes on entities. The integrated assessment of the scenarios was performed by analyzing the materials derived from the performance/experience and from the analysis of the initial and final states of the entities. The objective was to assess the interactions among the agents, observing the usage of the resources and the behavioral effects of the socio-ecological system.

\section{Results of The Maxwell Demon case study}

6.1 Contingencies. We consider interactions and behaviors leading to sound discovery as sources of contingencies. Much of the material produced in the TMD sessions is rarely repeated, providing conditions for high creative potentials. The sounds produced by the algorithms are dynamically related to the actions of the agents. Nevertheless, a gelassenheit entity produces sound content that may or may not be imitated by or contrasted with the outcomes produced directly by the agents. In this sense, this guideline is analogous to Maxwell's imaginary entity.

6.2 Musical expertise. Although there were disparities of musical knowledge among the agents, all showed similar technical ability while trying to produce sounds. We observed similarities in the three performances/experiments, featuring intense agent interactions. The exchanges encompassed algorithms $\mathrm{x}$ agents, agents $\mathrm{x}$ agents and agents $\mathrm{x}$ environmental resources.

6.3 Imitation. We observed that a large part of the interaction process was driven by imitation (a strategy pointed out by Mannis, 2014). Changes of processing types and dynamic modification of parameters were predominant. In general, there was a prevalence of imitation of processes suggested by the musicians, but contents proposed by non-musicians were also present.

\section{Implications of the PESM in Comprovisation}

7.1 Socio-ecological systems. By introducing ecologically grounded sound synthesis strategies in improvised contexts, unique conditions are created for each performance. The performance/experiment TMD integrates the electronic sound sources into socially dynamic forms of interaction, thus approaching the complexity of biophonic ${ }^{10}$ ecologies. Being a comprovisational method, the PESM features material resources that can be used either as guidelines or as contingencies. When applying ecological synthesis and modeling strategies within socio-ecological systems, the aesthetic decisions may follow deterministic rules (through compositional plans) or adopt procedures based on contingencies (through improvisation). By adding resources based on sound synthesis and audio processing that depend 
on the agent's actions, both the material and the cognitive resources are directly linked to the dynamics of the socio-ecological system.

Exploratory behavior. Previous case studies (ALIEL et al., in press) indicate that the generation, maintenance and disappearance of sound material in improvised ecological contexts, while closely related to the creative potential supported by exploratory and by epistemic actions (KELLER et al., 2010), are enhanced by the agents' knowledge of the material resources. In TMD, we adopted similar protocols to previous studies but provided a stronger procedural path through the introduction of the PESM.

- Behaviors. The agents explored various material resources involving multiple forms of interaction. Their mobility - in addition to the low dynamic range of the sounds produced by the mobile devices - fostered a dynamic and highly concentrated sonic result in which the focus of attention changed constantly.

- Discovering the tools and the materials. The agents discovered material resources through their actions (initially, they had little familiarity with the tools). Since the participants must learn the operation of the tools while producing the sound, this demand set cognitive challenges that limit their opportunities to produce new material resources.

- Technical level of the agents. Although there were various levels of musical training among the stakeholders, the lack of specific technical knowledge of the tools enforced similar levels of creative potential, encouraging exploratory actions by all the participants.

- Exploration through gestures. This strategy entailed the use of imitation as a resource for material generation. While associated to exploratory activity, it produced a large quantity of material resources with a low index of creative potential;

- Exploration of environmental features. This strategy was associated with the direct use of material resources of the environment for the production of new aesthetic outcomes. In this case, the quality and quantity of the material resources was determined by the creative potential furnished by the environment.

\section{Final Considerations}

Taking into account Sibertin's and coauthors' socio-ecological approach and ecologically grounded creative practices (KELLER, 1999), we elaborated a Proposal for Ecological Synthesis Models (PESM). While expanding the range of ecocompositional applications, we investigated the possibility to include improvisation in creative sonic ecologies. The PESM was applied in a case study, The Maxwell Demon. The TMD experiment aimed to investigate the integration of electronic sounds in ecological environments while encouraging interactions between the agents and the machines. Three experimental sessions were carried out with the objective of collecting information on the agents' behaviors, on the sonic resources and on the technological support. These observations yielded strategies applicable to ecologically grounded artistic works targeting both musicians and non-musicians.

Based on the observed outcomes, we conclude that the exploratory and epistemic activities are closely related to the available material resources. While the exploratory actions may yield new material and cognitive resources, through constant exchanges between the stakeholders the epistemic actions focus on the management of the cognitive strategies without introducing new material resources. Despite their differences, these activities 
are not dissociated. Tools and resources are incorporated by the agents in the face of necessity. As pointed out by Sibertin-Blanc et al. (2011), decision making depends on the restrictions and on the opportunities afforded by adapted behaviors (see introduction).

Among the limitations of the study, we can mention the absence of a structured musical product (thus, it is not possible to literally replicate the outcomes in other occasions). Another limitation was the use of a controlled environment (the studio) reducing the range of contingencies (within the context of TMD these contingencies were termed Gelassenheit). with a broader range of agents (of different ages and previous experiences). Another factor that could be investigated further is the role of musical training. Musicians and untrained agents could be engaged to compare procedures and types of solutions by groups with different profiles. It is reasonable to claim that applications involving different profiles of agents in less restricted environments could lead to a larger variety of outcomes. Despite these shortcomings, the results of this exploratory study indicate a fruitful path to artistic strategies to be added to the growing body of ecologically grounded creative practices.

\section{Notes}

1 Experiments developed to assess artistic results qualitatively or quantitatively

2 See also relational properties, recently proposed in (Keller et al., 2015). [

3 This term comes from computer science. The concept of instance corresponds to the existence of an object that shares some characteristics with another item or object. For example: despite some singularities (type of instruments, technical training, sonic preferences, etc.), all musicians have similar characteristics to other individuals of the same class (such as their musical training encompassing domain-specific knowledge.

4 Imminence of the observation of an entity.

5 Sonic pregnancy has also been used by some authors. For the sake of simplicity and to avoid the profusion of ter$\mathrm{ms}$, we stick to the standard usage of creative potential.

6 There are pure environmental contingencies that can not be quantitatively measured or evaluated because their measurement involves errors or indeterminacy. The concept of sonic gelassenheit indicates the ability to describe a specific quality of a sound mass (HEIDEGGER, 1985; KOUTSOMICHALIS, 2011). It can only be experienced subjectively.

7 A closely related criticism has been articulated within the context of ecologically grounded creative practice (BOWN et al., 2009; KELLER, 2000; KELLER; LAZZARINI, 2017). The acoustic-instrumental paradigm adopts instrumentally oriented concepts - such as the orchestra, the traditional notation systems or the virtuosic performance - as measures of effective support provided by digital musical interaction designs. Ecological approaches strive to provide a wider perspective on design, applicable both to professional and everyday creative practices.

8 From an ecocompositional perspective, the use of accumulation is associated with sonic material resources created by adding layers of material, yielding sound textures (KELLER, 2000; KELLER et al. 2002).

9 We use the term "independence" in the sense that actions are not fully controlled by the biological agents.

10 Animal sound sources

\section{References}

ALIEL, Luzilei. Essays on Comprovisation in Sonic Ecologies: Empirical and Theoretical Perspectives (Ensaios sobre Comprovisações em Ecologia Sonora: Perspectivas Práticas e Teóricas). Master in Music Thesis, São Paulo, SP: Universidade de São Paulo, 2017

ALIEL, L.; KELLER, D.; COSTA, R. Comprovisation: Approaches from Aesthetic Heuristics in Ecocomposition (Comprovisação Abordagens Desde a Heurística Estética em Ecocomposição). In Proceedings of the XV Symposium on Computer Music, Campinas, SP: SBCM, 2015.

ALIEL, Luzilei.; COSTA, Rogério; KELLER, Damián. Theoretical Perspectives for the Analysis of Ecocognitive creative practices (Perspectivas Teóricas para a Análise das Práticas Criativas Ecocognitivas). Per Musi. (In press). 
ALIEL, Luzilei.; FORNARI. José. Destino Pirilampo project: An study on composition of meta-soundscapes in ubiquitous music (Projeto Destino Pirilampo: Um Estudo sobre a Composição de Meta-Soundscapes em Música Ubíqua). Música Hodie, v.14, p. 105- 121, 2014.

BARREIRO, Daniel Luis; KELLER, Damián. Composing with sonic models: fundamentals and electroacoustic applications (Composição com modelos sonoros: fundamentos e aplicações eletroacústicas). In Damián Keller; Rogério Budasz (eds.), Criação musical e tecnologias: teoria e prática interdisciplinar, Vol. Criação Musical e Tecnologias: Teoria e Prática Interdisciplinar (pp. 97-126), 2010. Goiânia, GO: Editora ANPPOM.

CARDEW, Cornelius. A Scratch Orchestra: Draft Constitution. The Musical Times 110 (1516), 617-619, 125th Anniversary Issue, 1969.

CHEN, Shan., PIN, Peter., The Entity-Relationship Model - Toward a Unified View of Data.

ACM Transactions on Database Systems 1 (1): 9-36, 1976.

CURRAN, Alvim; TEITELBAUM, Richard. MUSICA ELETTRONICA VIVA. For MEV,

program notes. New York: The Knitting Factory, 1989. http:/www.alvincurran.com/writings/ mev.html

DI SCIPIO, Agostino. A Sound is The Interface: From Interactive to Ecosystemic Signal Processing. Organised Sound 8(3):269-277, 2003.

DI SCIPIO, Agostino. The place and meaning of computing in a sound relationship of man, machines, and environment. In A. Georgaki; G. Kouroupetroglou (eds.), Proceedings of the ICMC $|S M C| 2014$. Athens, Greece: ICMA. 2014.

DUDAS, Richard. Comprovisation: The Various Facets of Composed Improvisation within Interactive Performance Systems. Leonardo Music Journal 20, p. 29-31. 2010.

FANTAUZZACOFFIN, Jill; ROGERS, Juan D. Considering patterns of creative work process in creativity support. In Proceedings of the ACM CHI Conference on Human Factors in Computing Systems (CHI'13). Paris, France, 2013.

FERRAZ, Silvio; KELLER, Damián. Preliminary proposal of the MDF model of collective creation (MDF: Proposta preliminar do modelo dentro-fora de criação coletiva). Cadernos de Informática 8 (2), 57-67, 2014.

IGLESIA, Daniel. The Mobility is the Message: the Development and Uses of MobMuplat. In: Pure Data Conference (PdCon16). New York, 2016. http://www.danieliglesia.com/mobmuplat/ IglesiaMobMuPlatPaper.pdf.

GIAMPIETRO, Mario. Complexity and Scales: The Challenge for Integrated Assessment. Integrated Assessment 3 (2-3), 247-265. 2002.

KELLER, Damián. touch'n'go: Ecological Models in Composition. Master of Fine Arts Thesis, Burnaby, BC: Simon Fraser University.

http://www.sfu.ca/sonic-studio/srs/EcoModelsComposition/Title.html. 1999.

KELLER, Damián. Sonic Ecologies. In A. R. Brown (ed.), Sound Musicianship: Understanding the Crafts of Music (pp. 213-227). Newcastle upon Tyne, UK: Cambridge Scholars Publishing, 2012. (ISBN: 978-1-4438-3912-9.)

KELLER, Daniel., BARREIRO, Daniel. Luis., QUEIROZ, Marcelo; PIMENTA, Marcelo. Soares. Anchoring in ubiquitous musical activities. In Proceedings of the International Computer Music Conference (pp. 319-326). Ann Arbor, MI: MPublishing, University of Michigan Library, 2010. 
KELLER, Damián., LAZZARINI, Victor; PIMENTA, Marcelo. Soares. Ubimus through the lens of creativity theories. In D. Keller; V. Lazzarini; M. S. Pimenta (eds.), Ubiquitous Music (pp. 3-23). Berlin and Heidelberg: Springer International Publishing, 2014. (ISBN: 978-3-319-11151-3.)

HEIDEGGER, Martin. Gelassenheit. Revista de la Sociedad Argentina de Filosofía 3, p. 109-119, 1985. Translated by E. Caletti and A.P. Carpio.

KOUTSOMICHALIS, Marinos. Site Specific Live Electronic Music: A Sound Artist's Perspective. Proceedings of the Electroacoustic Music Studies Conference, Sforzando!, New York. 2011. Accessed 22 April 2016. http://www.emsnetwork.org/IMG/pdf_EMS11_Koutsomichalis.pdf

LATOUR, Bruno. Reassembling the social: An introduction to Actor-Network Theory. Oxford, UK: Oxford University Press, 2005.

MANNIS. José Augusto. Processos Cognitivos de Percepção, Análise e Síntese Atuando no Processo Criativo Mimesis de Mimesis. In Encontro Nacional de Composição Musical de Londrina (EnCom 2014), 2014.

PAHL-WOSTL, Claudia. Transitions towards adaptive management of water facing climate and global change. Water Resources Management 21, p. 49-62. 2007.

REED, Mark. Stakeholder participation for environmental management: A literature review.

Biological Conservation 141, p. 2417-2431, 2008.

RHODES, Mel. An analysis of creativity. The Phi Delta Kappan 42, p. 305-311. 1961.

ROTMANS, Jan.; ASSELT, Marjolein. Integrated assessment: A growing child on its way to maturity. Climatic Change 34 (3), p. 327, 1996.

SIBERTIN-BLANC, Chrisophe; THÉROND, Olivier; MONTEIL, Claude; MAZZEGA,

Pierre. Formal modeling of social- ecological systems. In: European Social Simulation Association Conference (ESSA 2011). Montpelier: Cemagref. 2011.

Luzilei Aliel - Graduado em Música com ênfase em Educação Musical pela Universidade Federal de São Carlos (UFSCar, 2012), Mestrado em Processos Criativos, obtido na Escola de Comunicação e Artes da Universidade de São Paulo (2017). Doutorando em processos criativos na Universidade de São Paulo (2018).

Dámian Keller - Possui doutorado em tecnologia e composição musical pela Universidade Stanford (2004) e mestrado interdisciplinar em arte pela Universidade Simon Fraser (1999). Realizou pós-doutoramento em ciência da computação na Universidade Federal do Rio Grande do Sul (2012). Atualmente é professor associado na Universidade Federal do Acre, onde lidera o grupo de pesquisa NAP - Núcleo Amazônico de Pesquisa Musical. Tem experiência nas áreas de computação musical, composição musical, cognição musical, interação humano-computador, atuando principalmente nos seguintes temas: música ubíqua, ecocomposição, design criativo, arte multimídia. É um dos fundadores da rede de pesquisa Grupo de Música Ubíqua

Rogério Costa - Possui o diploma de Licenciatura em Artes com Habilitação em Música (1983), mestrado em Musicologia (2000), ambos pela USP, e doutorado em Comunicação e Semiótica pela PUC-SP (2003). Atualmente é professor livre docente e pesquisador vinculado ao Programa de Pós-Graduação em Música da Escola de Comunicações e Artes da USP. Tem experiência na área de artes, com ênfase em composição, teoria e análise musical. Seu principal tema de investigação é a improvisação e suas conexões. 